\title{
MODELLING OF CARBON MONOXIDE AIR POLLUTION IN LARG CITIES BY EVALUETION OF SPECTRAL LANDSAT8 IMAGES
}

\author{
M. Hamzelo ${ }^{a^{*}}$, A. Gharagozlou ${ }^{\text {b }}$, S. Sadeghian ${ }^{\text {b }}$, SH. baikpour ${ }^{\text {a }}$, A. Rajabi ${ }^{\text {c }}$ \\ a Faculty of Environment and Energy, Islamic Azad University, Science and Research Branch, Tehran - \\ hamzelo2maryam@gmail.com, sh.baikpour@srbiau.ac.ir

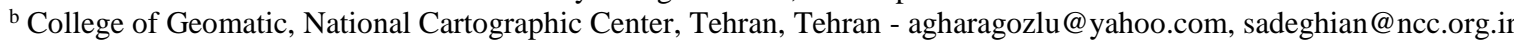 \\ ${ }^{c}$ Dept. of Surveying Engineering, Faculty of Engineering, University of Isfahan, Isfahan - ahmadrajabi222@gmail.com
}

KEY WORDS: Modelling, Air Pollution, Carbon Monoxide, LANDSAT8 images

\begin{abstract}
:
Air pollution in large cities is one of the major problems that resolve and reduce it need multiple applications and environmental management. Of The main sources of this pollution is industrial activities, urban and transport that enter large amounts of contaminants into the air and reduces its quality. With Variety of pollutants and high volume manufacturing, local distribution of manufacturing centers, Testing and measuring emissions is difficult. Substances such as carbon monoxide, sulfur dioxide, and unburned hydrocarbons and lead compounds are substances that cause air pollution and carbon monoxide is most important. Today, data exchange systems, processing, analysis and modeling is of important pillars of management system and air quality control. In this study, using the spectral signature of carbon monoxide gas as the most efficient gas pollution LANDSAT8 images in order that have better spatial resolution than appropriate spectral bands and weather meters،SAM classification algorithm and Geographic Information System (GIS ), spatial distribution of carbon monoxide gas in Tehran over a period of one year from the beginning of 2014 until the beginning of 2015 at 11 map have modeled and then to the model valuation ccreated maps were compared with the map provided by the Tehran quality comparison air company. Compare involved plans did with the error matrix and results in 4 types of care; overall, producer, user and kappa coefficient was investigated. Results of average accuracy were about than $80 \%$, which indicates the fit method and data used for modeling.
\end{abstract}

\section{Introduction}

Harmful substances, in excess of natural compounds in the atmosphere by natural phenomena or air pollution caused by human activities, called air pollution. Different kinds of pollution in the atmosphere come from human activities and natural phenomena like forest fires and desert storms. These two factors can produce a thick cloud of pollution about hundreds of kilometers away from their original source. There are Strong evidence that the severe effects of various forms of air pollution on water, soil, plants, deforestation, and human health. Pollution parameters are measured by remote sensing. The problem of remote sensing techniques is that it can't measure pollution parameters directly and remote sensing techniques gain information by optical of the earth climate system. But their advantages are including the possibility of measuring on the natural conditions and providing information of the entire pollution system via satellite in vast area. On the other hand The field measurements are performed in the local volume and area that they have some inherent problems in sampling. However, the thickness of the light pollution from satellites is less accurate than ground (terrestrial) measurements. Satellite measurements provide wide spatial coverage which in combination with models and ground measurements can be useful to determine the air quality at a lower cost. The disadvantages (defects) of ground measurements make it necessary to develop remote sensing techniques. Developments in satellite remote sensing for monitoring air quality at local and regional scales caused a new field of information (Kaufman, 1998). Accessing to satellite facilities required for each pollutant measurement of air pollution in this way will be much cheaper and more convenient. It can be said that the most important pollutants in the big cities of Iran, are the particles suspended. Given the importance of this issue at the present time, due to the fact that earlier studies of this kind in the country rarely done, the need to check out this issue and identifying and solving problems that are related to it, is very clear. Recently, many studies on atmospheric particles suspended monitoring were done by remote sensing technology. TolgaElbir has studied a Research titled \"GIS-based decision support system for the estimation, visualization and analysis of air pollution in big cities of Turkey $\backslash "$ in 2004. In this research, decision support systems to support the local authorities are discussed in the management of air quality in big cities of Turkey. This system is based on dispersion models CALPUFF, digital maps and related database to estimate the spatial distribution of greenhouse gas emissions and air pollutants (Elbir, 2004). Sohrabinia and colleagues (Sohrabinia\& el.) have examined pollution in Tehran in an article titled $\backslash$ "using satellite data and GIS in the study of air pollution in Tehran \" in 2007 .In this study particles and dust maps extracted from MODIS images. Collection of pollution is displayed by Using GIS. It is used ground stations data to generate different maps of each pollutant separately and finally the quantitative of dust MODIS data were compared with spatial data networks (Sohrabinia, 2007). TolgaElbir and collaborate (TolgaElbir\& el.) on the other research have developed offered decision support system in the studying 2004, in 2010 (Elbir, 2010). Mohammed Hashim, in an article in 2010 from satellite image processing used ETM7 sensor in sixth band (thermal infrared) and Geographic Information System (GIS) for determining the air pollution and its relationship with land cover and land use in the (city of) Baghdad. In this study, the concentration of total suspended particles $\mathrm{Pb}, \mathrm{CO}, \mathrm{CO} 2$ and $\mathrm{SO} 2$ Obtained from 22 ground measurement stations that these station are distributed to the industrial, commercial and residential categorized in Baghdad. Digital numbers on site field research stations for measuring air pollutants have become to the values of radiation and brightness temperature sensor and ground surface temperature in satellite images (Mohammed Hashim, 2010). Ch. Vlachokostas and colleagues combined air quality and geographic information systems modeling to estimate the amount of damage to crops 
from photochemical pollution in a study airing 2010.The research is in the area of Thessaloniki in Greece Mediterranean region that is at a high level of photochemical pollution, which has significant agricultural activity. Changing the thickness of the ozone layer has been modeled in this area between 2002 and 2010 and damage to the goods has been checked. The highest damage is entered to cotton (M16) and then tomatoes (M9) rice (M4.2) and wheat (M4) (Ch. Vlachokostas, 2010). Chao Wang and colleagues (Chao Wang \& el.) have created data collection for monitoring air quality in urban scale MODIS satellite image in a study titled $\backslash$ "evaluation of air quality in urban scale based on satellite imagery MODIS ।" In 2013. In this study, the concentration of aerosol optical (AOT) at $1 \mathrm{~km}$ resolution has been recovered by using the improved algorithm of MODIS Terra satellite. AOT AOT 1 kilometer has been validated by using measurements of AOT from AERONET stations and results have been Validated of AOT 10 kilometers of MOD04_L2 AERONET are in the October 2004 (Wang, 2013). Fikret Tuna\& colleagues have done a research as \ "analysis for PM10Pollutants in Istanbul using Kriging and IDW methods (between 2003 and 2012) $\backslash "$ in 2015 to investigate the air pollution in Istanbul .The aim of this study was to analyze the spatial distribution of air pollution in Istanbul using IDW and Kriging method in GIS (PM10 data from different years). Information for PM10 Pollutants from 2003, 2006, 2009 and 2012 have been obtained and analyzed from eight different measuring air pollution stations (Tuna, 2015). Due to the above, to promote pollution data derived from satellite imagery in this study, the possibility of air pollution monitoring carbon monoxide (CO) in the atmosphere in Tehran, has been studied as the most important particles of air pollution, using Landsat8satellite images. In order to introduce the model for detecting these Pollutants by using satellite images. Distribution map monoxide Carbone detected from the image with ground measurements, Concentration of this Pollutants Were compared by matrix error In Tehran. This comparison indicates the overal accuracy of about $80 \%$, the result of two types of data. The reviewed model, has a fairly good ability to determine the concentration of carbon monoxide in Tehran

\section{The case study area}

Tehran is one of the most polluted cities in the world. The main pollutants in the atmosphere in Tehran are in Table 1. According to this table the largest portion is carbon monoxide and the least portion is sulfur ans its about 17 thousand tons. Several factors are involved in Tehran infections that geographic factors are the most important among them. Tehran Longitudes 51 to 51.66 degrees and latitude is 35.5 to 35.58 degrees. With an area about $800 \mathrm{~km} 2$ on the southern slopes of the Alborz in a Half-closed environment that the height of the southern city in the Mehrabad airport is 1200 meters and it is 2000 meters in the north of Tehran. Alborz Mountains in the north and north-eastern blocked Western Wind, and caused that all Pollutants remain in the city. Great inversion conditions and continuous deployment of high pressure systems over the years are the region's natura features that they cannot be modified or eliminated. On the other hand, human factors like high population and the establishment of factories in the city, Increase the city's pollution levels, especially in the West and the South West. The lack of efficient management and planning in order to solve the problem and lack of cooperation of the people also contributed to the cause. In the current situation, which Tehran is as the mastermind and management of the country and most of the policies and laws that regulated in it. Cleaning the air and create a conducive environment to thinking and deciding is considered crucial to its strategy on the other hand Tehran's air pollution will not only lead to Tehran and the effects of polluted air even at great distances can be seen in Firoozkooh or Garmsar Therefore, Tehran pollution has become to a regional and national problem. Tehran's air cleaning increases health of Tehran and health of Iran. Obviously for cleaning air of Tehran changing any of the Natural elements is not possible and changing the location of capital needs time and money. Meanwhile, environmental factors are important in the first stage therefore, this paper tries to identify the factors influencing the amount and how to consider them to be able to assist planners and policy makers. According to statistics the Environmental Protection Agency and data obtained from the investigation written some researchers, the most important factors influencing Tehran's air pollution are the topography, climate, population, industry, and urban transport network

\begin{tabular}{|c|c|c|c|c|c|}
\hline $\begin{array}{c}\text { Nitrogen } \\
\text { oxides }\end{array}$ & Sulfur & Aerosols & Hydrocarbons & $\begin{array}{c}\text { Carbon } \\
\text { monoxide }\end{array}$ & Pollutant \\
\hline 104 & 17 & 21 & 116 & 1284 & $\begin{array}{c}\text { Density } \\
\text { by } 1000 \\
\text { ton }\end{array}$ \\
\hline
\end{tabular}

Table 1. The main air pollutants in Tehran

\section{The used data}

\subsection{Air pollution monitoring data from ground stations}

Tehran has about 20 measure air pollution stations across the city is established currently that the number of stations owned by the control of air pollution in Tehran. These stations are measuring the amount of pollutants such as carbon monoxide, sulfur dioxide, nitrogen dioxide, ozone and particulate matter during the day and night.

\subsection{Landsat8 Satellite data}

Landsat8 satellite was launched on February 11, 3112.Landsat8 will ensure continuous data collection and availability of Landsat data by using two sensors, one of them is Operational Land Imager (OLI) and the other is Thermal Infrared Sensor (TIRS). The two sensors are collecting image information for 9 Short wave band and 2 Length heat wave band respectively. By presenting images of medium resolution of $15 \mathrm{~m}, 30 \mathrm{~m}$ and 100 $\mathrm{m}$ of the surface and the polar regions have been used Landsat 8 in the range of visible light, NIR (near-infrared), SWIR (short wave infrared) and TIR (thermal infrared).

\section{Research Methodology}

Harvest date of Landsat8 data used in this study, is an OLI sensor image per month in Tehran from the first month until the last month of 2014. Although satellite data have been corrected before offering to users in different levels of geometric and radiometric, there is ability to maintain some basic errors or errors resulting from the initial correction process that the images were evaluated again. After correction, using the supervised classification algorithms SAM and carbon monoxide spectral reflectance curve as training data, created distribution maps of this feature and for evaluating, using the confusion matrix, obtained maps of classification were compared with Company's quality control air pollution in Tehran's maps.

\subsection{Spectral Angle Mapper (SAM)}

Supervised classification is a Multispectral method to classify the pixels based on their similar spectral characteristics in this method the operator selects the properties of classification personally. This method is done in two ways first; the operator can select small areas in satellite images that have the same mode in their amounts of reflect number these areas are as teaching districts or training districts and each of them is said a class. These areas are obtained based on field visits and using different maps. Then the remaining image pixels are classified 
according to the number of pixels supervised classes. In the second method operator can use the database and spectral library. Values of each pixel compared with the existing data of reflectance spectra of various complications. And similar pixels are chosen as the class. Spectral angle mapping methods are including conventional methods of supervised classification that is done by the second way .with spectral similarity between the spectra of reflection image and reference, specifies the location of the desired effects in the image, or in other words, calculates the angle between the whole spectrum of each pixel and the whole phenomenon of interest smaller angles between the spectra shows more similarity and larger angles show less similarity (Richards, 2005). SAM Algorithms, using the reflectance spectrum of carbon monoxide, have been implemented on images and the results of it for displaying and better interpretation, became the ArcGIS software to density map of carbon monoxide. The curved shape of the reflection spectrum of carbon monoxide and density map of carbon monoxide pollution for January 2014 is showing the distribution of carbon monoxide in the region they are shown In Figures 1 and 2 .

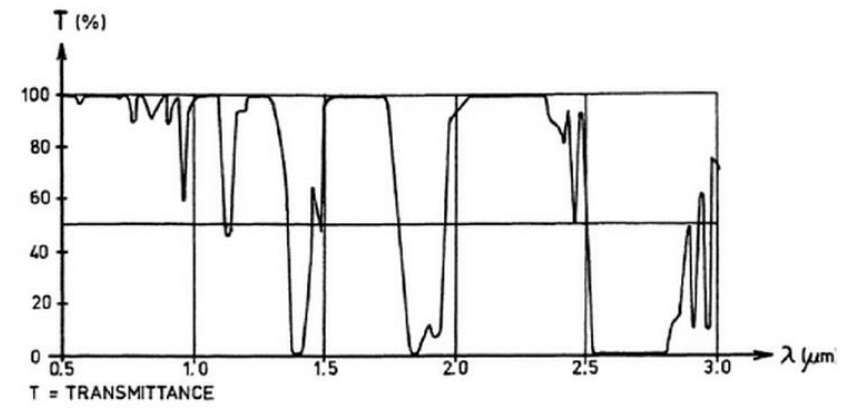

Figure 1. Reflects the whole curve of carbon monoxide (Rueger, 1996).

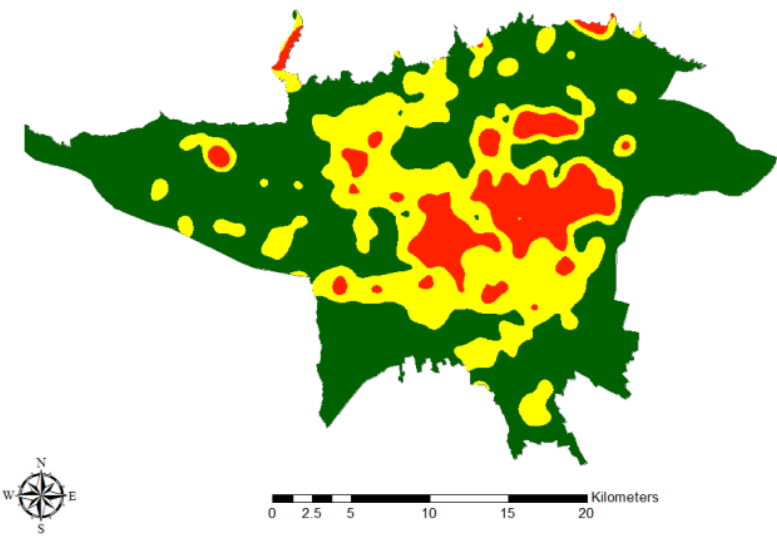

Figure 2. Density map of carbon monoxide pollution in Tehran for January 2014 (green: Clear, Yellow: low density, red: high density)

\section{Results and discussion}

At this stage to assess the correctness and accuracy of the maps from SAM method used of comparing its results with the results of ground stations in isolated parts of the region, by confusion matrix in this context, the term of accuracy and precision are known it means the agreement between the tag set by the SAM classification method on Landsat8 data and allocation class to ground stations data by GIS. Appropriate steps can be acquainted us in order to measure the accuracy and precision of the classification with the classification performance. considered Methods in this section is based on analysis of the confusion matrix that is the most common tool used for evaluating the classification precision After forming The confusion matrix for classification results were obtained on each map, overall precision, production precision, and the precision of kappa coefficient users, which is shown in figure.

According to the Numbers constituent of confusion matrix, it is necessary to point out that the imbalance of the number of pixels of different classes makes Map fluctuation and kappa coefficient, which may be too good or bad, and it is not reliable. The high number of pixels in other classes also makes the number on the diagonal of the confusion matrix very high and thus increases the overall precision. Finally, we can say that the using of user and manufacturer precision for carbon monoxide can be more reliable than others.

The results of confusion matrix in the 11 months of the study area indicate that Identification and mapping of carbon monoxide by using SAM pixel method on multispectral Landsat8 images has an average overall accuracy top of $76 \%$, $47 \%$ producer accuracy, $22 \%$ user accuracy and 0.53 kappa coefficient for confusion matrix. In the 2,3,4,5 Tables and 3 figures, the density maps of carbon monoxide pollution in the 11 months of the year 2014 measuring carbon monoxide with the number of ground stations in the city and the precision obtained from the error matrix for each map.

Interestingly, the result is that when we used data from more stations to compare, we've found a better accuracy for confusion matrix. This implies that for getting a correct measurement, we need to more stations on the ground. The Landsat 8 satellite images had good performance under the SAM algorithm. This can be used for pollution monitoring station in any land, in determining the concentration of pollution.

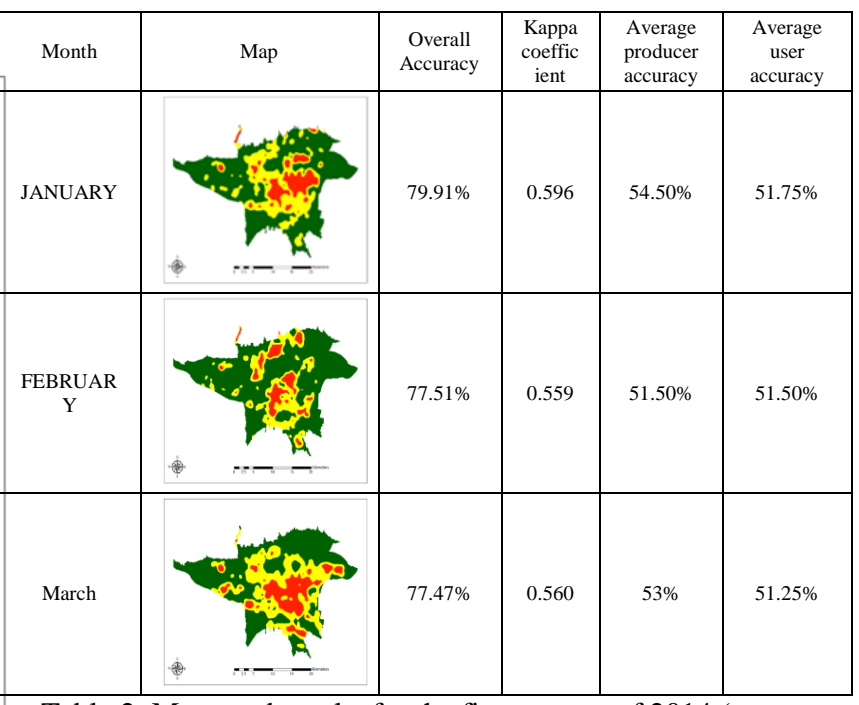

Table 2. Maps and results for the first quarter of 2014 (green: Clear, Yellow: low density, red: high density)

\begin{tabular}{|c|c|c|c|c|c|}
\hline Month & Map & $\begin{array}{c}\text { Overall } \\
\text { Accuracy }\end{array}$ & $\begin{array}{c}\text { Kappa } \\
\text { coefficient }\end{array}$ & $\begin{array}{c}\text { Average } \\
\text { producer } \\
\text { accuracy }\end{array}$ & $\begin{array}{c}\text { Average } \\
\text { user } \\
\text { accuracy }\end{array}$ \\
\hline APRIL & \multirow{2}{*}{$*$} & & & & \\
& & $73.58 \%$ & 0.4859 & $45 \%$ & $43.25 \%$ \\
\hline
\end{tabular}




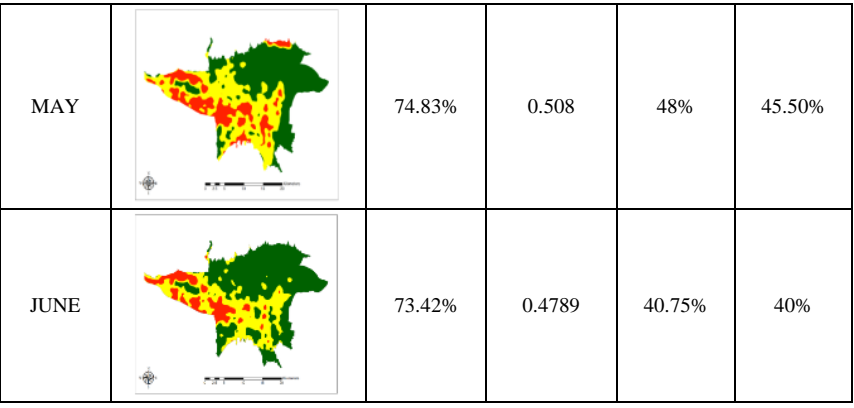

Table 3. Maps and results for the second quarter of 2014 (green: Clear, Yellow: low density, red: high density)

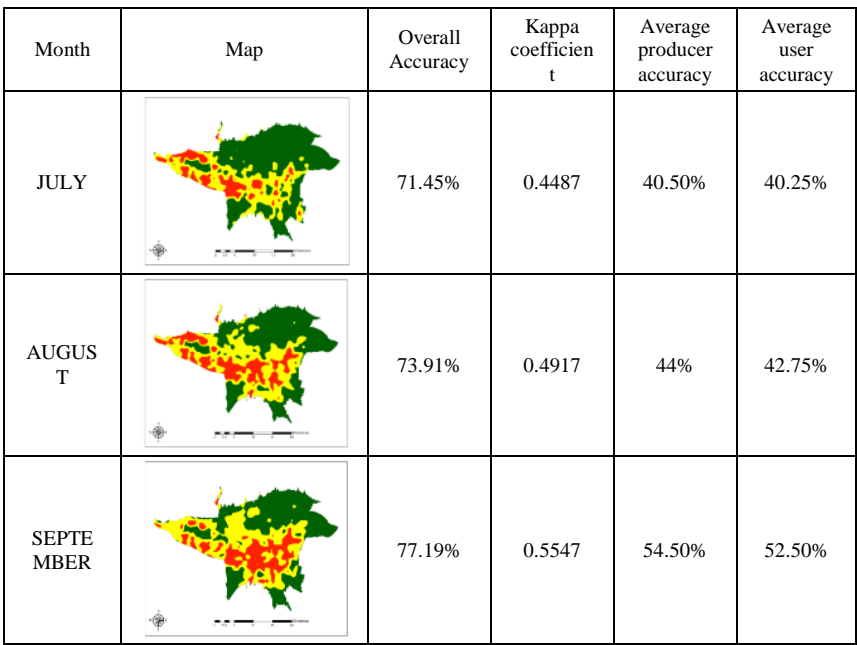

Table 4. Maps and results for the third quarter of 2014 (green: Clear, Yellow: low density, red: high density)

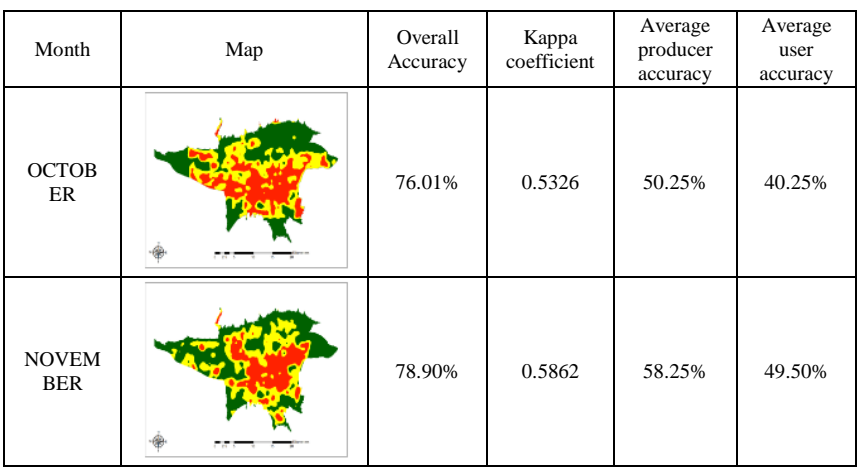

Table 5. Maps and the results of the last two months of 2014 (green: Clear, Yellow: low density, red: high density)

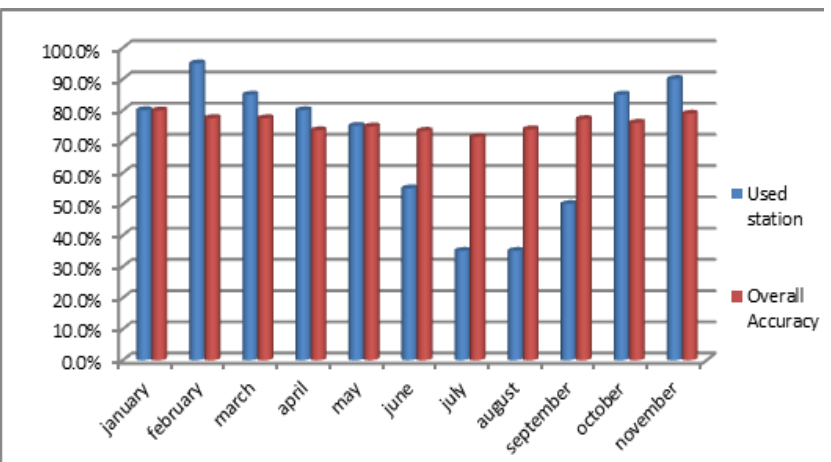

Figure 3. Comparison charts between stations and overall accuracy per month

\section{Conclusion}

The study conducted in this study it concluded that recent developments in the field of remote sensing have provided. The possibility of using satellite images to measure contaminants in natural conditions and in large urban areas and even country using of this knowledge leads to a significant reduction in costs and labor compared with land-based techniques, due to the availability of satellite facilities in the country, the cost of air pollution monitoring using satellite imagery is very low, Because preparation images is free And it can be easily obtain from the Internet And using the technology monitor air pollution. In this study, the possibility of measuring carbon monoxide pollution in the atmosphere in Tehran, with the using Landsat8images has been studied. To this, the SAM classification algorithm to detect carbon monoxide emissions were using Landsat8 image within 11 months of the year 2014 the pollution density map derived from images were compared with ground-based measurements of pollutants concentration, using the confusion matrix. This comparison indicates the overall average precision top of $21 \%$ between the results of these two types of data. The using images and models, has good ability to determine the concentration of pollutants in the city of Tehran.

\section{Suggestion}

It is suggested that researchers in the field of air pollution information extracted from satellite images, for better evaluation of satellite images and extract more information from algorithms band relation in the near-infrared and the middle bands and the thermal imaging thresholding of the modeling and spatial distribution of contamination and then created the valuation models, maps created with maps provided by the company to measure air quality in Tehran compare.

\section{REFFERENCE}

1- Kaufman, J., Tanré, D., 1998. Algorithm for remote sensing of tropospheric aerosol from MODIS, IEEE transactions on geoscience and remote sensing, 35:1286-1298.

2- Elbir, T., 2004. A GIS basedd decision support system for estimation, visualization and analysis of air pollution for largeTurkish cities, Elsevier, Atmospheric Environment 38, $4509-4517$.

3- Sohrabinia, M., Khorshiddoust, AM., 2007. Application of satellite data and GIS in studying air pollutants in Tehran. Habitat International, 31: 268-275.

4- Elbir, T., Mangir, N., 2010. Development of a GIS-based decision support system for urban air quality management in the city of Istanbul, Elsevier, Atmospheric Environment 44, $441 \mathrm{e} 454$.

5- Mohammed Hashim, B., Abdullah Sultan M., 2010. Using remote sensing data and GIS to evaluate air pollution and their relationship with land cover and land use in Baghdad City, Iranian Journal of Earth Sciences, 2 / 20-24.

6- Vlachokostas, CH., Nastis, S.A., 2010. Economic damages of ozone air pollution to crops using combined air quality and GIS modeling, Elsevier, Atmospheric Environment 44, 3352e336.

7- Wang, Ch., Liu, Q., 2013. Air quality evaluation on an urban scale based on MODIS satellite images, Elsevier, Atmospheric Research 132-133, 22-34. 
The International Archives of the Photogrammetry, Remote Sensing and Spatial Information Sciences, Volume XL-1/W5, 2015 International Conference on Sensors \& Models in Remote Sensing \& Photogrammetry, 23-25 Nov 2015, Kish Island, Iran

8- Tuna, F., Buluc, M., 2015. Analysis of PM10 Pollutant in Istanbul by Using Kriging and IDW Methods: Between 2003 and 2012, International Journal of Computer and Information Technology (ISSN: 2279 - 0764) Volume 04 - Issue 01, January.

9- Richards A., 2005. Remote Sensing Digital Image Analysis, Springer- Berlin Heidelberg, pp. 368-373.
10- Rueger J.M., 1996. Electronic Distance Measurement: An Introduction, Springer- Berlin Heidelberg, pp. 21-52. 